\title{
Estimation of the Na Insertion/Extraction Reaction Rate as the Na Chemical Diffusion Coefficient in Low-Temperature-Fired Soft Carbon
}

\section{Junji SUZUKI, ${ }^{a}, *$ Narumi KUBOTA, ${ }^{b}$ Yukikazu OMURA, ${ }^{b}$ Keisuke SUGATA, ${ }^{b}$ Kento KISA, ${ }^{b}$ Hiroaki SOFUJI, ${ }^{b}$ and Mayumi HATTORI ${ }^{a}$}

\author{
a Department of Science, National Institute Technology, Matsue College, \\ 14-4 Nishi-ikumacho, Matsue, Shimane 690-8518, Japan \\ b Department of Electrical Engineering, National Institute Technology, Matsue College, \\ 14-4 Nishi-ikumacho, Matsue, Shimane 690-8518, Japan
}

*Corresponding author: junji@matsue-ct.jp

\begin{abstract}
The development of SIB has attracted attention as a substitute for LIB. Low-temperature-fired soft carbon (LFSC) has been the target of study as SIB's useful negative electrode material. We estimated Na chemical diffusion coefficient $D_{\text {chem }}$ using the same approach and samples of previous report on LIB. The approach was potential step chronoamperometry (PSCA) method, and the samples were mesophase-pitch-based carbon fiber fired at four different low temperatures $\left(600,700,800\right.$ and $\left.950^{\circ} \mathrm{C}\right)$. The PSCA measurements by using a single LFSC fiber electrode were performed in an electrolyte of propylene carbonate (PC) containing $1 \mathrm{M} \mathrm{NaClO}_{4}$ at room temperature in a glove box filled with dried Ar. The largest $D_{\text {chem }}$ value we obtained with four pristine LFSC was about $10^{-9} \mathrm{~cm}^{2} /$ sec. The $D_{\text {chem }}$ values depended not only on firing temperature of LFSC but also on the nature of LFSC's surface. The effective surface treatment promoted $\mathrm{Na}$ insertion/extraction reaction rate on the carbon surface. The largest $\mathrm{Na} D_{\text {chem }}$ value we obtained after surface treatment was $10^{-8} \mathrm{~cm}^{2} / \mathrm{sec}$. This $\mathrm{Na} D_{\text {chem }}$ value was close to the Li $D_{\text {chem }}$ value $\left(10^{-7.5} \mathrm{~cm}^{2} / \mathrm{sec}\right)$ by previous report, which suggests possibility of SIB's practical use.
\end{abstract}

(C) The Electrochemical Society of Japan, All rights reserved.

Keywords : SIB Negative Electrode, Reaction Rate, Diffusion Coefficient, Soft Carbon

\section{Introduction}

Public demand has become stronger for rechargeable batteries with high power and long cycle life. Lithium-ion battery (LIB) provides high working voltage, specific capacity, and cyclability, and has long been applied to portable appliances such as laptop computers and mobile phones. Moreover, in recent years, LIB has widened its application range to vehicles such as electric vehicles (EV), hybrid electric vehicles (HEV) and plug-in hybrid electric vehicles (PHEV). ${ }^{1,2} \mathrm{Li}$ is one of the rare metals mined at limited places, and this wide application of LIB as well as political issues has raised its price. Accordingly, research and development of nextgeneration battery has prospered in search of the substitute of $\mathrm{Li}$, such as $\mathrm{Mg}, \mathrm{Ca}$ and $\mathrm{Na}^{3-11} \mathrm{Na}$, relatively easily available on the earth, is low in cost and has property similar to Li. In addition, metallic Na's redox potential is $-2.71 \mathrm{~V}$ vs. SHE, which is only $0.3 \mathrm{~V}$ higher than that of metallic Li. Therefore, the development of Sodium-ion battery (SIB) is expected as one of the most promising next-generation battery. ${ }^{6-11}$

The main type of negative electrode material used in LIB is graphite. However, graphite can't be utilized for SIB negative electrode, for the amount of $\mathrm{Na}$ that can be inserted into the graphite layers is limited. ${ }^{6}$ One of the active research target as a negative electrode material of SIB has been hard carbon. ${ }^{7-11}$ This is because hard carbon's non-crystalized structure with cavities promotes $\mathrm{Na}$ insertion/extraction. D. A. Stevens et al., ${ }^{8}$ S. Komaba et al. ${ }^{10}$ and K. Gotoh et al. ${ }^{11}$ described Na's accommodation mechanism in hard carbon and reported its insertion/extraction characteristics.

Meanwhile, low-temperature-fired soft carbon (LFSC) has also attracted attention as a negative electrode material in LIB. ${ }^{12-16}$ The highest capacity of LFSC is reported up to $900 \mathrm{mAh} / \mathrm{g}$, which is over twice that of graphitized carbon. ${ }^{12}$ LFSC is assumed to have two phases: one is oriented, and the other, non-oriented, which gradually changes according to the firing temperature rise. This structure is similar to that of hard carbon. LFSC's larger capacity compared with that of graphite is due to these two phases. Therefore, we can expect LFSC to have high storage property of $\mathrm{Na}$ like hard carbon. And in that case, LFSC could be useful negative electrode material of SIB. The accommodation mechanism of $\mathrm{Li}$ and $\mathrm{Na}$ in LFSC heated at $1000^{\circ} \mathrm{C}$ by in situ X-ray scattering scan was reported by D. A. Stevens et al. ${ }^{8}$ In their report, the Na insertion/ extraction into/from the oriented phase of LFSC occurred at a positive potential region $\left(1.0-0.1 \mathrm{~V}\right.$ vs. $\left.\mathrm{Na} / \mathrm{Na}^{+}\right)$. The $\mathrm{Na}$ insertion/ extraction into/from the non-oriented phase occurred at a negative potential region (less than $0.1 \mathrm{~V}$ vs. $\mathrm{Na} / \mathrm{Na}^{+}$).

In the view of $\mathrm{Li}$ diffusion in LFSC and $\mathrm{Li}$ insertion/extraction reaction rate into/from LFSC, $\mathrm{H}$. Kataoka et al. reported the possibility of the rapid movement of Li between two different phases of LFSC by NMR study. ${ }^{13}$ Y. Saito et al. reported the diffusion coefficient of $\mathrm{Li}$ in LFSC fired at different temperatures by the pulsed gradient spin echo NMR method. ${ }^{14}$ The value in LFSC fired at $800^{\circ} \mathrm{C}$ was about $10^{-7.5} \mathrm{~cm}^{2} / \mathrm{sec}$. O. Omae et al. reported the chemical Li diffusion coefficient $D_{\text {chem }}$ in LFSC fired at $800^{\circ} \mathrm{C}$ by potential step chronoamperometry (PSCA). ${ }^{15}$ The detail of PSCA method is shown as follows. 1) A cylindrical glass cell containing a two-electrode system was used for PSCA measurements. 2) The single carbon fiber (LFSC fired at $800^{\circ} \mathrm{C}$ ) was used as a working electrode and metallic Li foil was used as the counter electrode. 3) Propylene carbonate (PC) containing $1 \mathrm{M} \mathrm{LiClO}_{4}$ was used as an electrolyte solution. 4) The potential was kept at $10 \mathrm{mV}$ (vs. $\mathrm{Li} / \mathrm{Li}^{+}$) for inserting $\mathrm{Li}$ into carbon electrode. 5) The potential was stepped from $10 \mathrm{mV}$ to $100 \mathrm{mV}$ for extracting $\mathrm{Li}$ from carbon to electrolyte 
solution and the current-time curve was recorded. 6) Similarly, the potential was stepped every $100 \mathrm{mV}$ from $100 \mathrm{mV}$ to $800 \mathrm{mV}$. 7) The obtained current-time curves were analyzed by the Cottrell equation. Their value of $D_{\text {chem }}$ in sufficiently surface modified LFSC was $10^{-7.5} \mathrm{~cm}^{2} / \mathrm{sec}$.

Since these two values obtained by two different methods were almost the same, the value can be reliable. However, the information of diffusion coefficient of $\mathrm{Na}$ in LFSC fired at different temperatures has not been obtained yet.

In this paper, we try to estimate Na chemical diffusion coefficient $D_{\text {chem }}$ using the same approach (the Cottrell equation for analysis and PSCA by using a single carbon fiber electrode) and samples (mesophase-pitch-based carbon fiber: Melblon series) as O. Omae et al., for the PSCA method is simple with convenience. We compare our Na $D_{\text {chem }}$ with O. Omae et al.'s Li $D_{\text {chem }}$, trying to examine $\mathrm{Na}$ character.

\section{Experimental}

\subsection{Materials}

The structure of LFSC depends on the firing temperature. The non-oriented-micro-crystal in LFSC is gradually changed to oriented-crystal like a graphite structure with the increase of firing temperature. Hence some LFSCs namely Melblon 600, Melblon 700, Melblon 800 and Melblon 950 (Product of Petoca Materials, Co., Ltd., approx. $10 \mu \mathrm{m}$ in diameter), mesophase-pitch-based carbon fiber felt, were used as a negative electrode material. The number means the firing temperature. For example, Melblon 700 is fired at $700^{\circ} \mathrm{C}$, and Melblon 800 is fired at $800^{\circ} \mathrm{C}$. The SEM (Scanning electron microscopy) images of Melblon series are shown in Fig. 1. A single carbon fiber was picked out from the integrated fiber felt and used for the test electrode. The sample fiber was heated at $300^{\circ} \mathrm{C}$ in vacuum for 1 hour as a pretreatment in order to remove the absorbed contaminants like $\mathrm{a}_{2} \mathrm{O}$ on its surface.
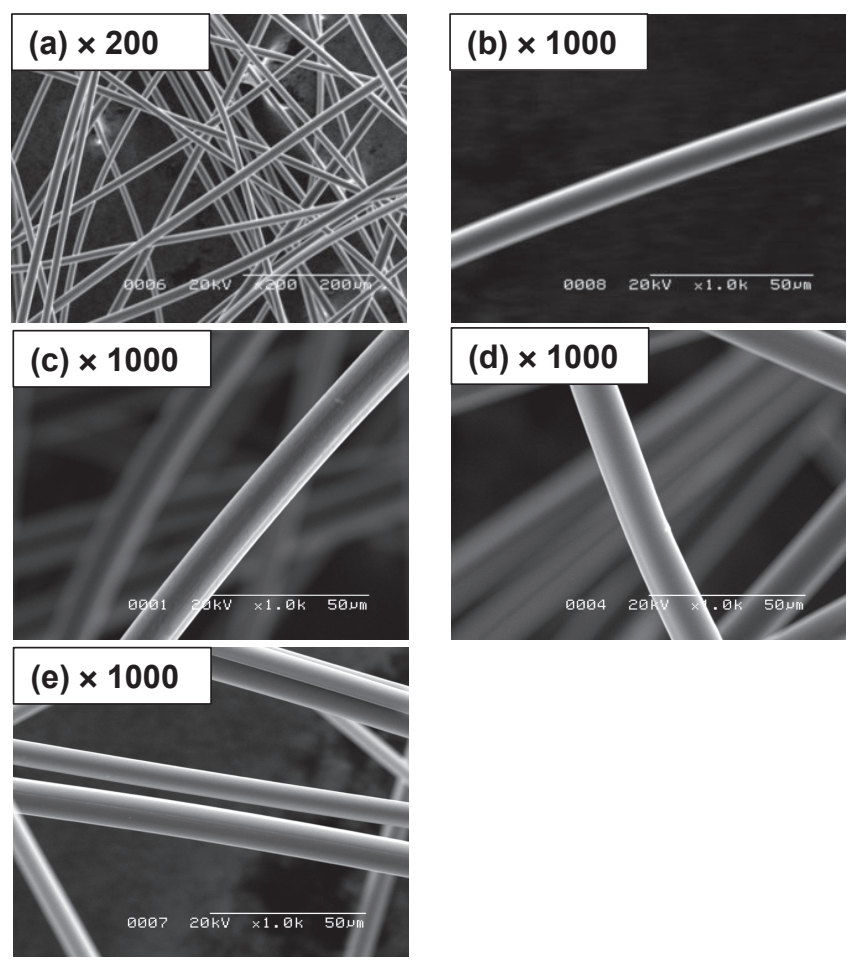

Figure 1. Scanning Electron Microscopy (SEM) images of the Melblon series. (a) Melblon $800(\times 200)$, (b) Melblon $800(\times 1000)$, (c) Melblon $600(\times 1000)$, (d) Melblon $700(\times 1000)$, (e) Melblon $950(\times 1000)$.

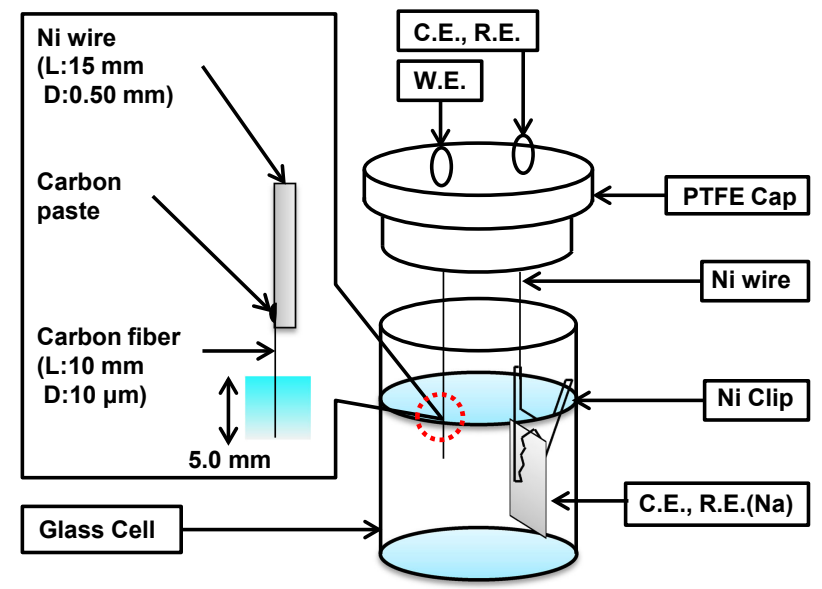

Figure 2. Schematic figure of the two-electrode-cell system.

\subsection{Electrochemical measurements}

A cylindrical Pyrex glass cell with a two-electrode system was used for the measurements (Fig. 2). A 15-mm-long sample fiber was fixed on one end of a $0.5-\mathrm{mm}$-diameter $\mathrm{Ni}$ wire with conductive carbon paste, and $5-\mathrm{mm}$ of the sample fiber is vertically immersed into an electrolyte as a negative electrode (W.E.). Using a single carbon fiber is advantageous for obtaining the most reliable data, and we can avoid the ambiguity of electrode size, the interference of binder and loosening the electrical contact in the coated type electrode. Pure metallic $\mathrm{Na}$ was used as a counter (C.E.) and reference electrode (R.E.).

Propylene carbonate (PC) containing $1 \mathrm{M} \mathrm{NaClO}_{4}$ was used as an electrolyte. The electrolyte solution with its water less than $30 \mathrm{ppm}$ was provided by Tomiyama Chemicals. Electrochemical measurement was conducted by a liner sweep cyclic voltammetry (CV) with a sweep rate of $0.1 \mathrm{mV} / \mathrm{sec}$ and by the current-time curves of potential step chronoamperometry (PSCA). A Bio-Logic Potentiostat-galvanostat type SP-150 was used for the electrochemical measurement. Our focus in this paper is on $\mathrm{Na}$ extraction reaction from carbon, which is directly related to the battery power. In PSCA measurement, the potential step range $(5-700 \mathrm{mV})$ was determined by current due to $\mathrm{Na}$ extraction reaction in CVs. The detail potential step method is shown as follows. 1) For checking the cell condition, 6 cycles of $\mathrm{CV}$ measurement with a sweep rate of $0.1 \mathrm{mV} / \mathrm{sec}$ was carried out. 2) The potential was kept at $5 \mathrm{mV}$ for 100 hours to insert $\mathrm{Na}$ into carbon sample. 3) The potential was stepped from $5 \mathrm{mV}$ to $100 \mathrm{mV}$, and kept at $100 \mathrm{mV}$ for 1 hour. 4) Similarly, the potential was stepped every $100 \mathrm{mV}$ from $100 \mathrm{mV}$ to $700 \mathrm{mV}$. All measurements were performed at room temperature in a glove box filled with dried air.

\subsection{Apparent diffusion coefficient $D_{\text {chem }}$ of $\mathrm{Na}$}

The Na chemical diffusion coefficients $D_{\text {chem }}$ in the carbon fiber sample were obtained by analyzing the PSCA current decay curves. The current decay curves were recorded by voltage-width, and Cottrell plots were obtained from the curves, some parts of which showed approximately straight lines. The value of $D_{\text {chem }}$ was estimated from the inclinations of these straight lines along each curve and the following Cottrell equation:

$$
j=n F\left(D_{\text {chem }}\right)^{1 / 2} C_{N a} /(\pi t)^{1 / 2}
$$

where $j\left[\mathrm{~A} / \mathrm{cm}^{2}\right]$ is the current density; $n$, the number of electrons involved in the electrode reaction; $F[\mathrm{C} / \mathrm{mol}]$, the Faraday constant $(96485 \mathrm{C} / \mathrm{mol}) ; C_{N a}\left[\mathrm{~mol} / \mathrm{cm}^{3}\right]$, the concentration of $\mathrm{Na}$ in the carbon electrode which was estimated by CV measurement; $t$ [sec], the time after the potential step. 


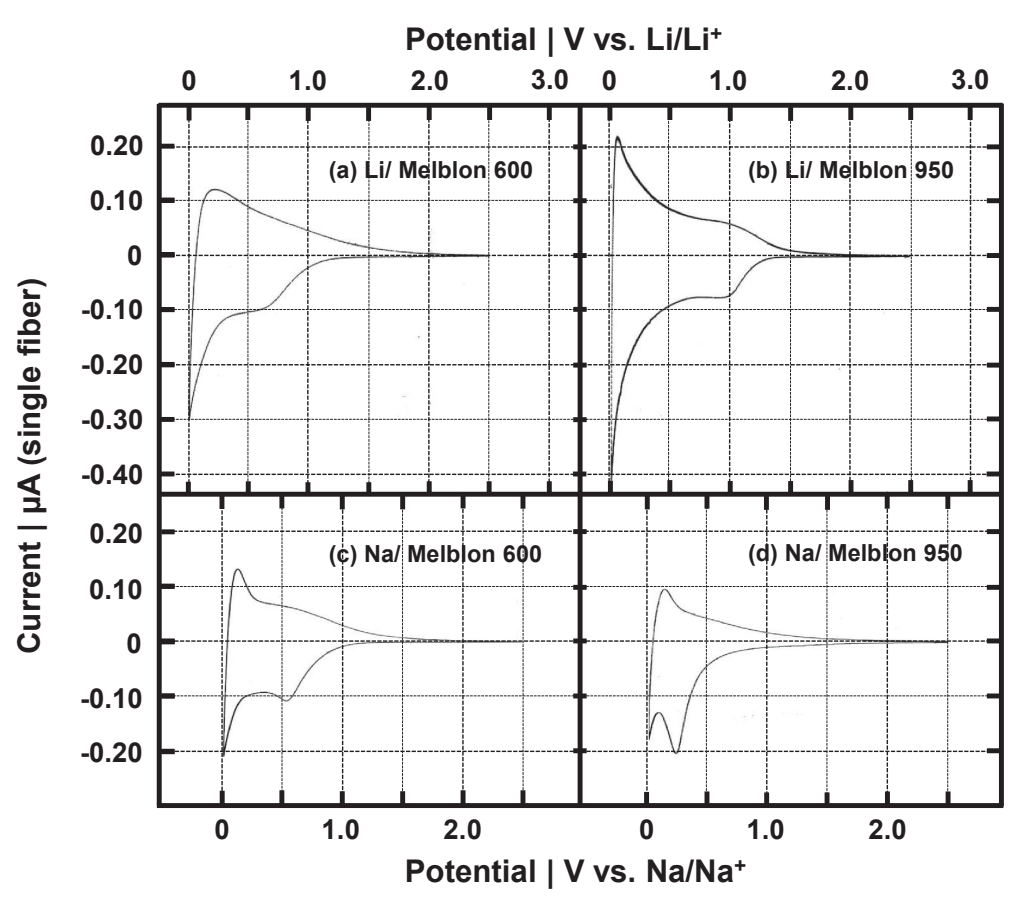

Figure 3. Cyclic voltammograms (CVs) of a single carbon fiber with potential sweep rate of $0.1 \mathrm{mV} / \mathrm{sec}$. (a) Melblon 600 in PC containing $1 \mathrm{M} \mathrm{LiClO}_{4}$, (b) Melblon 950 in PC containing $1 \mathrm{M} \mathrm{LiClO}_{4}$, (c) Melblon 600 in PC containing $1 \mathrm{M} \mathrm{NaClO}_{4}$, (d) Melblon 950 in PC containing $1 \mathrm{M} \mathrm{NaClO}_{4}$.

There are two reasons why the diffusion coefficient $D$ is expressed as the apparent diffusion coefficient $D_{\text {chem }}$.

In a strict sense, the Cottrell equation can be applied unless the rate-determining step of all reactions is controlled by the $\mathrm{Na}$ diffusion in carbon electrode. However, it is not clear yet where the rate-determining step happens in this study. The estimated $D$ values may not indicate diffusion coefficient but chemical reaction rate.

This Cottrell equation is applicable for planar electrodes, not for cylindrical electrodes like a carbon fiber. Generally, the diffusion equation for cylindrical electrode should be calculated by adopting the Fick's 2nd law of diffusion. Bansal et al. reported that the Cottrell equation is a limiting case for cylindrical equation and it is accurate only when $D$ is small $\left(D<10^{-5} \mathrm{~cm}^{2} / \mathrm{sec}\right), \mathrm{r}_{0}$ (the radius of the electrode) is large $\left(\mathrm{r}_{0}>2.6 \mathrm{~mm}\right)$ and $t$ is small $(t<1 \mathrm{sec}) .{ }^{19}$ According to Bansal et al.'s report, the diffusion current for cylindrical electrode is increased than that of planer electrode. In this case, the estimated $D$ value is larger than the true $D$ value because of adopting larger current than that of planer electrode. In our study, the estimated $D$ values were not so large. There is possibility that our $D$ values larger than approximately ten times larger than the true $D$ values.

Therefore, the estimated diffusion coefficients are apparent diffusion coefficients, and they are expressed as chemical diffusion coefficients $D_{\text {chem }}$. In this study, it should be kept in mind that the $D_{\text {chem }}$ values were not the true $D$ values but apparent $D$ values. These approach followed Omae's procedure..$^{15,16}$ One of our purposes is to compare our $\mathrm{Na} D_{\text {chem }}$ with O. Omae et al.'s Li $D_{\text {chem }}$, and we used the same approach as O. Omae et al. in order to accomplish our purpose.

\section{Results and Discussion}

The CV measurement results of Melblon 600 and Melblon 950 showed characteristic of $\mathrm{Li}$ and $\mathrm{Na}$ 's insertion/extraction reaction into/from typical LFSC (Fig. 3). The CVs were in the 5th cycle. At first, even a single carbon fiber of $10 \mu \mathrm{m}$ in diameter and $5 \mathrm{~mm}$ in length showed excellent cycle performance in CV. Two peaks appeared on both the cathodic and the anodic branches. According to D. A. Stevens et al.'s report, this may imply that two phases exist in LFSC: one is oriented-phase (positive potential region) and the other is non-oriented-phase (negative potential region). In the case of Melblon 600, Li was inserted into carbon fiber at around $1.20 \mathrm{~V}$ (vs. $\mathrm{Li} / \mathrm{Li}^{+}$) and the current increased suddenly at around $0.35 \mathrm{~V}$ (vs. $\mathrm{Li} / \mathrm{Li}^{+}$) due to $\mathrm{Li}$ insertion (Fig. 3(a)). Na was inserted into carbon fiber at around $1.2 \mathrm{~V}$ (vs. Na/Na ${ }^{+}$) and the current increased suddenly at around $0.10 \mathrm{~V}$ (vs. $\mathrm{Na} / \mathrm{Na}^{+}$) due to $\mathrm{Na}$ insertion (Fig. 3(c)). The insertion potential converted to SHE potential was not so different between $\mathrm{Li}$ and $\mathrm{Na}$. In the case of Melblon 950, Li was inserted into carbon fiber at around $1.35 \mathrm{~V}\left(\mathrm{vs} . \mathrm{Li} / \mathrm{Li}^{+}\right)$and the current increased suddenly at around $0.35 \mathrm{~V}$ (vs. $\mathrm{Li} / \mathrm{Li}^{+}$) due to $\mathrm{Li}$ insertion (Fig. 3(b)). Na was inserted into it at around $1.60 \mathrm{~V}$ (vs. $\mathrm{Na} / \mathrm{Na}^{+}$) and two current peaks appeared clearly due to $\mathrm{Na}$ insertion (Fig. 3(d)). The drastic difference of these CVs shapes (Figs. 3(b), (d)) might imply that the small and limited amount of $\mathrm{Na}$ can be inserted into graphite layers. The $\mathrm{CV}$ measurements were carried out by $0.1 \mathrm{mV} / \mathrm{sec}$. This means that the $\mathrm{x}$-axis indicates not only the potential but the time. Since y-axis shows electric current, the quantity of electricity could be estimated. We have estimated discharge capacity by measuring the quantity of electricity and the mass of carbon material (calculated by its density and volume) for reference. The discharge capacities of a single fiber cited from each CVs in Fig. 3 were (a) $388 \mathrm{mAh} / \mathrm{g}$, (b) $433 \mathrm{mAh} / \mathrm{g}$, (c) $258 \mathrm{mAh} / \mathrm{g}$, (d) $171 \mathrm{mAh} / \mathrm{g}$.

The discharge capacities obtained from various LFSC single fiber cited from each CVs are showed (Table 1). For comparison, the capacity evaluated from CVs with fiber felt samples is also shown in Table 1 . The felt sample was cut into $3.0 \mathrm{mg} 1 \times 1 \mathrm{~cm}$ square sheet, heated at $300^{\circ} \mathrm{C}$, and sandwiched in between two $\mathrm{Ni}$ expanded sheets. The capacity of single fiber is higher than that of fiber felt at any firing temperature. This indicates that single fiber is more reliable without conductivity loss due to the contact with other carbon fibers. The capacity decreases with the increase of firing temperature. This tendency also implies the difficulty of $\mathrm{Na}$ insertion into the oriented phase. 
Table 1. The discharge capacities of a single fiber and felt fiber cited from CVs.

\begin{tabular}{lcccc}
\hline & \multicolumn{4}{c}{ Discharge capacity | mA h/g } \\
\hline Sample & Mel. 600 & Mel. 700 & Mel. 800 & Mel. 950 \\
Fiber felt & 163 & 108 & 152 & 128 \\
Single fiber & 258 & 226 & 182 & 171 \\
\hline
\end{tabular}

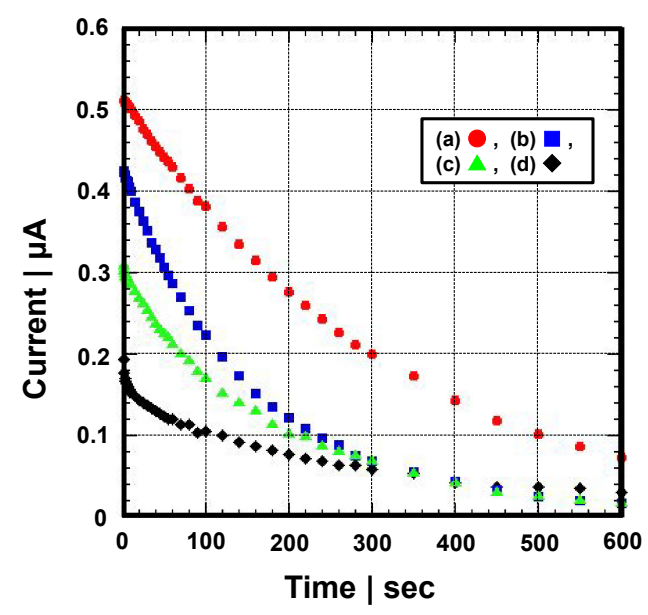

Figure 4. Discharging current decay curves of a single carbon fiber (Melblon 700) obtained in $\mathrm{PC}$ containing $1 \mathrm{M} \mathrm{NaClO}_{4}$ by PSCA. (a) 5-100 mV, (b) $200-300 \mathrm{mV}$, (c) $400-500 \mathrm{mV}$, (d) 600 $700 \mathrm{mV}$.

The Na insertion/extraction reaction depends on the potential, and PSCA method was applied for evaluating potential dependence of diffusion as $D_{\text {chem }}$. The current decay curves of Melblon 700 are shown in Fig. 4 in different potential stepping ranges. The current is highest with stepping in the range of 5-100 $\mathrm{mV}$. The Cottrell plots obtained from the current decay curves and its linear approximation for current vs. $t^{-1 / 2}$ were shown in Fig. 5.

Figure 6 shows the $D_{\text {chem }}$ values of various firing temperature LFSCs. Among all the four LFSCs, Melblon 700 showed larger $D_{\text {chem }}$ values (ca. $10^{-9} \mathrm{~cm}^{2} / \mathrm{sec}$ ). Melblon 700 and Melblon 800 showed larger values than Melblon 600 and Melblon 950. The $D_{\text {chem }}$ values of Melblon 600 were small in spite of its highest discharge capacity (Table 1). The reason of this is not yet elucidated. The correlation is not clear between $D_{\text {chem }}$ values and potential step ranges, excepting for potential step range of 5-100 mV. Except Melblon 800, the $D_{\text {chem }}$ values estimated from potential step range of 5-100 $\mathrm{mV}$ are clearly higher than 100-700 mV (Figs. 6(a), (b), (d)). This may indicate that $\mathrm{Na}$ extraction reaction rate from non-oriented phase is higher than that from oriented phase with each LFSC. In such a case, the largest $D_{\text {chem }}$ value could be expected with Melblon 600 , but in fact, the $D_{\text {chem }}$ value with Melblon 600 was small. The different surface condition and inter structure in each LFSC might complicate the matters. In the case of Melblon 800, the unfavorable surface condition might have brought different potential dependency (Fig. 6(c)). All the LFSC's $D_{\text {chem }}$ values of $\mathrm{Na}$ are smaller than those of Li by O. Omae's report. ${ }^{15}$

Someone may doubt the reliability of all the $D_{\text {chem }}$ values in Fig. 6, for the Cottrell equation for planer electrode was applied into the calculation of $D_{\text {chem }}$ values and all $D_{\text {chem }}$ values may be unreliable and meaningless values. However, the reliability of these $D_{\text {chem }}$ values can be confirmed by the following simple calculation. Figure 5(a) is the Cottrell plot obtained by the potential step of 5$100 \mathrm{mV}$ in Melblon 700. The value of $\mathrm{x}$-axis that we were based in

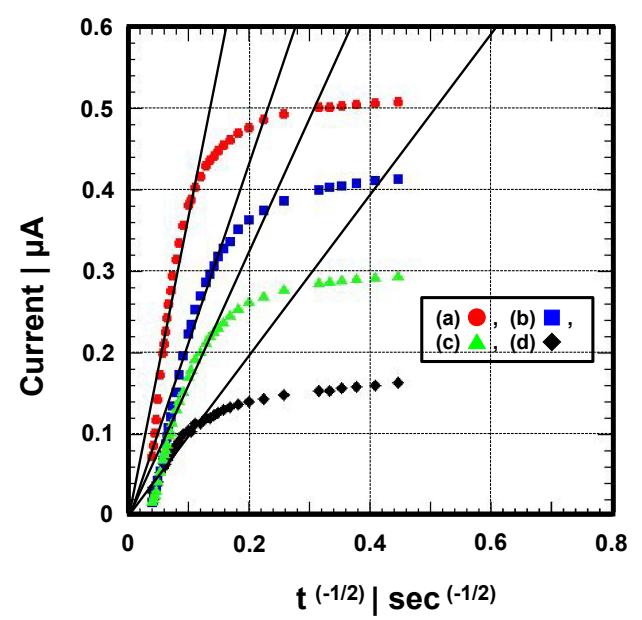

Figure 5. Cottrell plots of Fig. 4. (a) 5-100 mV, (b) $200-300 \mathrm{mV}$, (c) $400-500 \mathrm{mV}$, (d) $600-700 \mathrm{mV}$.

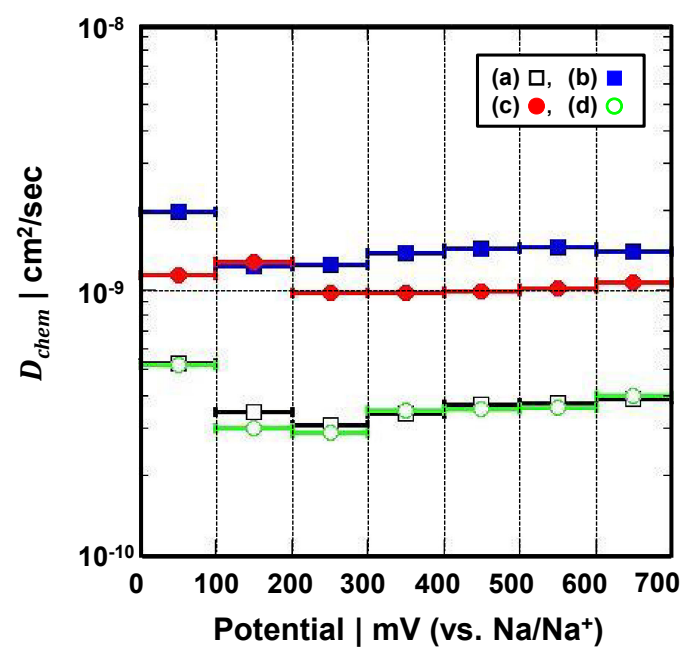

Figure 6. Chemical diffusion coefficient $D_{\text {chem }}$ of $\mathrm{Na}$ for a single carbon fiber fired at low temperature during $\mathrm{Na}$ extraction reaction. (a) Melblon 600, (b) Melblon 700, (c) Melblon 800, (d) Melblon 950 .

defining of the slope is about 0.1 , which is approximately $100 \mathrm{sec}$. Figure 6(b) shows Na $D_{\text {chem }}$ of Melblon 700 , and the $D_{\text {chem }}$ value in $5-100 \mathrm{mV}$ is estimated at about $2.0 \times 10^{-9} \mathrm{~cm}^{2} / \mathrm{sec}$. In general, the thickness of the diffusion layer $\mathrm{L}$ is considered to be the square root of $\mathrm{D} \mathrm{t}$ (D: diffusion coefficient, t: time), namely $\mathrm{L}^{2}=\mathrm{D}$ t. The square root of $2.0 \times 10^{-9} \mathrm{~cm}^{2} / \mathrm{sec}$ times $100 \mathrm{sec}$ equals $4.5 \mu \mathrm{m}$ (the thickness of the diffusion layer), which is almost the same as the radius of carbon fiber electrode. Although the radius of carbon fiber electrode is not utilized in our Cottrell equation, the estimated value of the diffusion layer corresponds to the radius of carbon fiber electrode.

If the rate-determining step of $\mathrm{Na}$ insertion/extraction reaction were surface reaction such as electron transfer reaction etc., the obtained $D_{\text {chem }}$ values would not be true value. If that is the case, the surface reaction becomes faster and the $D_{\text {chem }}$ values might get larger and approximately true value by surface treatment. We tried some effective surface treatment methods in LIB which is reported in: ${ }^{15-18}$ such as mild oxidation treatment (MOT), metal film deposition on carbon surface (MFD) and the combination of MFD and MOT. This paper reports the most effective method we have tried. The concrete method is shown as follows. 1) Melblon 800 is covered with $90 \mathrm{~nm}$ thick $\mathrm{Ag}$ film by vacuum deposition, and heated at $350^{\circ} \mathrm{C}$ in vacuum 


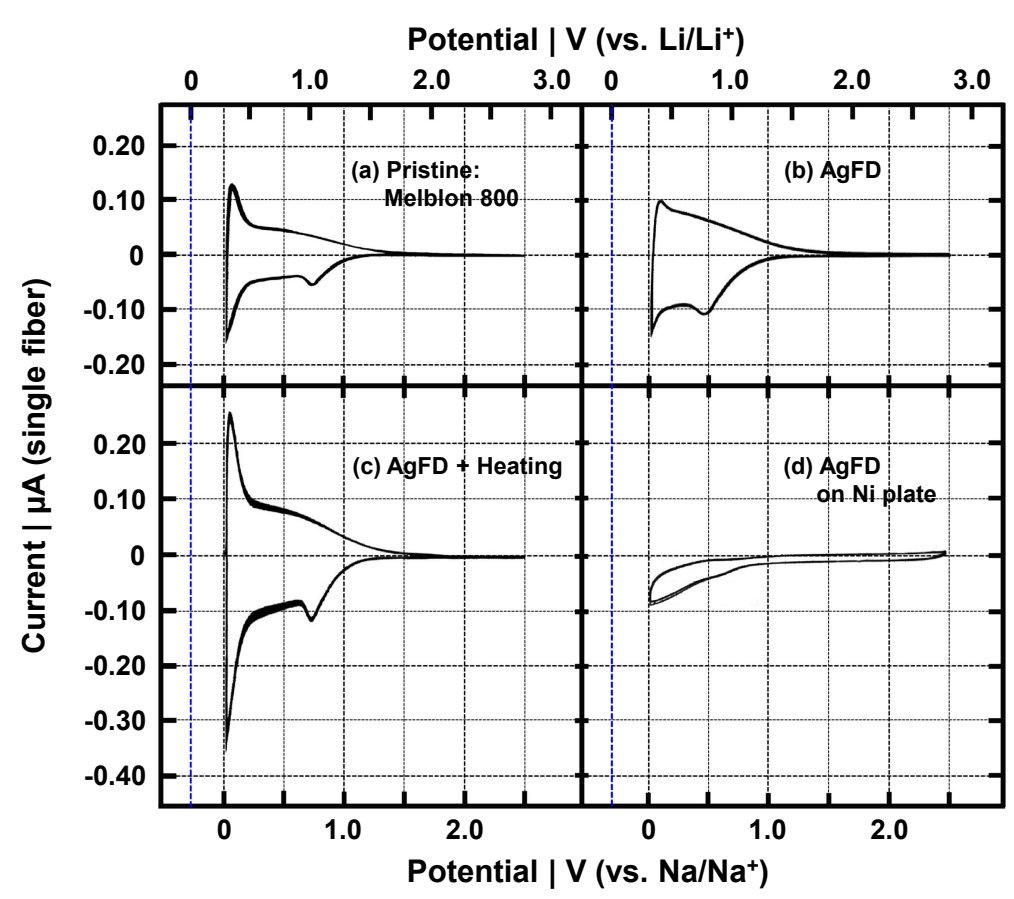

Figure 7. CVs of a single carbon fiber (Melblon 800 , in $\mathrm{PC}$ containing $1 \mathrm{M} \mathrm{NaClO}_{4}$, potential sweep rate: $0.1 \mathrm{mV} / \mathrm{sec}$ ) with and without surface modification. (a) Pristine, (b) covered with $90 \mathrm{~nm}$-thick $\mathrm{Ag}$ film, (c) heated for 1 hour in reduced air pressure at $350^{\circ} \mathrm{C}$ after the $\mathrm{Ag}$ film deposition, (d) $\mathrm{CVs}$ of a vacuum deposited $90 \mathrm{~nm}$-thick $\mathrm{Ag}$ film on a Ni plate in $\mathrm{PC}$ containing $1 \mathrm{M} \mathrm{NaClO}_{4}$, potential sweep rate: $0.1 \mathrm{mV} / \mathrm{sec}$.

for 1 hour, 2) Ag on the carbon surface melts and coagulates into tiny drops, 3) Tiny Ag drops spread all over the carbon surface.

The CVs of carbon samples with surface treatment were shown in Fig. 7. In the case of $\mathrm{Ag}$ film deposited sample, the peak current was once decreased (Fig. 7(b)). However, in the case of Ag film deposited and heated sample, the peak current drastically increased (Fig. 7(c)). This indicates that the reaction rate on the carbon surface increased. For reference, the discharge capacity cited from CVs in Fig. 7(c) was $320 \mathrm{mAh} / \mathrm{g}$, which could be enough capacity as SIB negative electrode material.

One may suspect that $\mathrm{Na}$ insertion/extraction into/from $\mathrm{Ag}$ accelerated and gave the increase of discharge capacity. But there would be little probability of that. $\mathrm{Na}$ insertion/extraction reaction into/from $\mathrm{Ag}$ was not detected in $\mathrm{CV}$ measurement (scan rate: $0.1 \mathrm{mV} / \mathrm{sec}$ ) for $90 \mathrm{~nm}$-thick Ag film on Ni plate (Fig. 7(d)). In addition, if $\mathrm{Na}$ insertion/extraction into/from $\mathrm{Ag}$ accelerates and contributes to the discharge capacity, the capacity would increase by simple Ag deposition (Fig. 7(b)). The electrode of a single fiber has no adhesion between the each fiber. Therefore, there would also be little probability that conductivity improvement enhanced electrode performance. This surface treatment could have worked to change the factors that slow down the surface reaction.

Detailed mechanism that enhances the reaction rate has not been elucidated yet. F. Kikuchi et al. reported the reason about $\mathrm{Li}$ insertion/extraction reaction enhancement for LIB graphite negative electrode. ${ }^{17}$ In the case of simple Ag film deposition on graphitized carbon fiber, decrease of surface-film resistance and charge-transfer resistance were detected by impedance measurement. In the case of the combination of Ag film deposition and heating, the surface-film resistance did not decrease much but the charge-transfer resistance drastically decreased. This could imply that the surface was activated by Ag melting and coagulating. We believe that the same phenomena took place in $\mathrm{Na}$ insertion/extraction with the combination of $\mathrm{Ag}$ film deposition and heating.

The $D_{\text {chem }}$ of Na obtained with LFSC was summarized in Fig. 8 . One may speculate that the $D_{\text {chem }}$ values could be enhanced at the same level by surface treatment at any potential, but the actual

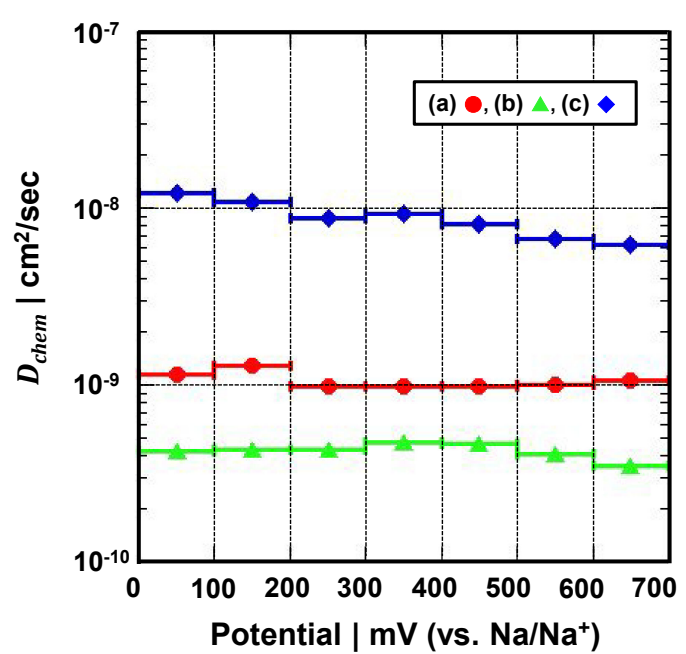

Figure 8. $D_{\text {chem }}$ of $\mathrm{Na}$ for a single carbon fiber (Melblon 800) with and without surface treatment. (a) Pristine, (b) covered with $90 \mathrm{~nm}$ thick Ag film, (c) heated for 1 hour in reduced air pressure at $350^{\circ} \mathrm{C}$ after the Ag film deposition.

increase tendency depends on potential range. $D_{\text {chem }}$ values are higher in low potential range than in high potential range (Fig. 8(c)). The combined surface treatment was effective in lower potential range, which promoted $\mathrm{Na}$ extraction from non-oriented phase, though its mechanism has not been elucidated yet. Simple Ag film deposition treatment eliminated $D_{\text {chem }}$ value's potential dependency (Fig. 8(b)). According to these results, the combined surface treatment might have brought out the more fundamental nature of LFSC in Na extraction reaction. Anyway, detailed research for demonstrating the mechanism of the surface treatment should be done. The highest $D_{\text {chem }}$ value in Fig. 8 was about $10^{-8} \mathrm{~cm}^{2} / \mathrm{sec}$. The surface treatment could remove unfavorable surface reactions. This surface treatment might promote $\mathrm{Na}$ insertion/extraction reaction 
rate into/from the carbon surface and bring out larger $\mathrm{Na}$ diffusion coefficient in LFSC. Altogether, $D_{\text {chem }}$ depends on the surface condition of carbon, and the $D_{\text {chem }}$ values could become larger. Here, we can conclude that the Na chemical diffusion coefficient $D_{\text {chem }}$ in LFSC (Melblon 800) is $10^{-8} \mathrm{~cm}^{2} / \mathrm{sec}$ at the moment and it could be improved with more effective surface treatments.

\section{Conclusion}

We estimated chemical diffusion coefficient $D_{\text {chem }}$ of $\mathrm{Na}$ in Melblon $600,700,800$ and 950 by PSCA method. Among these LFSCs, Melblon 700 showed larger $D_{\text {chem }}$ values $\left(\mathrm{ca} .10^{-9} \mathrm{~cm}^{2} / \mathrm{sec}\right.$ ). We tried several kinds of surface treatments to enhance $\mathrm{Na}$ insertion/extraction reaction into/from carbon, and reported the most effective method at the moment. The method was the combination of $\mathrm{Ag}$ film deposition and heating in a reduced air pressure. This surface treatment enhanced the $D_{\text {chem }}$ value of Melblon 800 (ca. $10^{-8} \mathrm{~cm}^{2} / \mathrm{sec}$ ). This implies that many more surface treatments could improve $\mathrm{Na} D_{\text {chem }}$. There is a possibility of $\mathrm{Na} D_{\text {chem }}$ getting closer to Li $D_{\text {chem }}$, in spite of Na's larger mass and ion diameter than Li. More detailed studies need to be made in order to examine $\mathrm{Na}$ character minutely. Recently, L. Xiao et al. reported the $\mathrm{Na}$ diffusion coefficient in polyaniline with hard carbon nanoparticle. $^{20}$ The $D_{\text {chem }}$ values obtained by electrochemical impedance spectroscopy were $10^{-10}-10^{-13} \mathrm{~cm}^{2} / \mathrm{sec}$. The electrode was coated type electrode, and their $D_{\text {chem }}$ values were much smaller than our $D_{\text {chem }}$ values. We ascribe these different $D_{\text {chem }}$ values to the following reasons: one is the difference of carbon materials (hard carbon/soft carbon), and the other is electrode type (coated type/ single carbon fiber). Simple comparison of $D_{\text {chem }}$ values is difficult and sometimes is not suitable, but our using a single carbon fiber is advantageous for obtaining reliable data. We can avoid the ambiguity of electrode size, the interference of binder, and loosening the electrical contact, which could happen in the coated type electrode. Therefore, we believe our results are more reliable. In addition, it is expected that the true $\mathrm{Na} D_{\text {chem }}$ value in LFSC could be larger than $10^{-8} \mathrm{~cm}^{2} / \mathrm{sec}$ by adopting more effective surface treatments.
At the moment, we can conclude that the Na $D_{\text {chem }}$ in Melblon 800 is $10^{-8} \mathrm{~cm}^{2} / \mathrm{sec}$. We will try to estimate $D_{\text {chem }}$ in other firing temperature LFSCs with surface treatment to confirm the surface treatment's effects. Many more methods are desired to perform to estimate $D_{\text {chem }}$. The relation between crystal structure of LFSC and $D_{\text {chem }}$ are also needed to be examined.

\section{References}

1. J. M. Tarascon and M. Armand, Nature, 414, 359 (2001).

2. M. Yoshio, R. J. Brodd, and A. Kozawa, Lithium-Ion Batteries; Science and Technologies, Springer, LaVergne, 2009.

3. T. Abe, Electrochemistry, 80, 89 (2012)

4. N. Yoshimoto, M. Matsumoto, M. Egashira, and M. Morita, J. Power Sources, 195, 2096 (2010).

5. M. Hayashi, H. Arai, H. Ohtsuka, and Y. Sakurai, J. Power Sources, 119-121, 617 (2003).

6. B. L. Ellis and L. F. Nazar, Curr. Opin. Solid State Mater. Sci., 16, 168 (2012).

7. D. A. Stevens and J. R. Dhan, J. Electrochem. Soc., 147, 1271 (2000).

8. D. A. Stevens and J. R. Dhan, J. Electrochem. Soc., 148, A803 (2001).

9. R. Alcántara, J. M. Jiménez Mateos, and J. L. Tirado, J. Electrochem. Soc., 149, A201 (2002).

10. S. Komaba, W. Murata, T. Ishikawa, N. Yabuuchi, T. Ozeki, T. Nakayama, A. Ogata, K. Gotoh, and K. Fujiwara, Adv. Func. Mater, 21, 3859 (2011).

11. K. Gotoh, T. Ishikawa, S. Shimadzu, N. Yabuuchi, S. Komaba, K. Takada, A. Goto, K. Deguchi, S. Ohki, K. Hashi, T. Shimizu, and H. Ishida, J. Power Sources, 225, 137 (2013).

12. I. Mochida, C.-H. Ku, S.-H. Yoon, and Y. Korai, J. Power Sources, 75, 214 (1998).

13. H. Kataoka, Y. Saito, O. Omae, J. Suzuki, K. Sekine, T. Kawamura, and T. Takamura, Electrochem. Solid-State Lett., 5, A10 (2002).

14. Y. Saito, H. Kataoka, K. Nakai, J. Suzuki, K. Sekine, and T. Takamura, J. Phys. Chem. B, 108, 4008 (2004).

15. O. Omae, J. Suzuki, T. Katsuta, K. Yamaguchi, F. Kikuchi, K. Sekine, T. Kawamura, and T. Takamura, Solid State Ionics, 152-153, 105 (2002).

16. O. Omae, J. Suzuki, T. Katsuta, K. Yamaguchi, F. Kikuchi, K. Sekine, and T. Takamura, Int. Solid State Ionics, Abstr., p. 25 (2001).

17. F. Kikuchi, S. Eguchi, J. Suzuki, K. Sekine, and T. Takamura, Electrochemistry, 71, 1117 (2003).

18. T. Takamura, S. Eguchi, J. Suzuki, O. Omae, and K. Sekine, J. Power Sources, 146, 129 (2005)

19. N. P. Bansal and J. A. Plambeck, Can. J. Chem., 56, 155 (1978).

20. L. Xiao, Y. Cao, W. A. Henderson, M. L. Sushko, Y. Shao, J. Xiao, W. Wang, M. H. Engelhard, Z. Nie, and J. Liu, Nano Energy, 19, 279 (2016). 